OPEN ACCESS

Edited by:

Bin Ren,

University of Alabama at Birmingham,

United States

Reviewed by:

Marie-José Goumans,

Leiden University Medical Center,

Netherlands

Chunsik Lee,

Sun Yat-sen University, China

${ }^{*}$ Correspondence:

Suk-Won Jin

sukwonjin@gist.ac.kr

Specialty section:

This article was submitted to

Signaling,

a section of the journal

Frontiers in Cell and Developmental

Biology

Received: 27 February 2021

Accepted: 21 May 2021

Published: 21 June 2021

Citation:

Han O, Pak B and Jin S-W (2021)

The Role of BMP Signaling

in Endothelial Heterogeneity.

Front. Cell Dev. Biol. 9:673396.

doi: 10.3389/fcell.2021.673396

\section{The Role of BMP Signaling in Endothelial Heterogeneity}

\author{
Orjin Han, Boryeong Pak and Suk-Won Jin*
}

Cell Logistics Research Center, School of Life Sciences, Gwangju Institute of Science and Technology (GIST), Gwangju, South Korea

Bone morphogenetic proteins (BMPs), which compose the largest group of the transforming growth factor- $\beta$ (TGF- $\beta$ ) superfamily, have been implied to play a crucial role in diverse physiological processes. The most intriguing feature of BMP signaling is that it elicits heterogeneous responses from cells with equivalent identity, thus permitting highly context-dependent signaling outcomes. In endothelial cells (ECs), which are increasingly perceived as a highly heterogeneous population of cells with respect to their morphology, function, as well as molecular characteristics, BMP signaling has shown to elicit diverse and often opposite effects, illustrating the innate complexity of signaling responses. In this review, we provide a concise yet comprehensive overview of how outcomes of BMP signaling are modulated in a context-dependent manner with an emphasis on the underlying molecular mechanisms and summarize how these regulations of the BMP signaling promote endothelial heterogeneity.

Keywords: heterogeneity, endothelium, BMP signaling, post-translational modification, computational modeling

\section{INTRODUCTION}

Endothelial cells (ECs) exhibit great heterogeneity (Aird, 2003), in their developmental origin (Bautch and Caron, 2015; Pak et al., 2020), morphology (Sailem and Al Haj Zen, 2020), as well as gene expression (Chi et al., 2003). With technical advances, the concept of endothelial heterogeneity has been re-evaluated and extended at the single-cell level (Nolan et al., 2013; Kalucka et al., 2020), which re-ignited the interest in signaling pathways essential for modulating endothelial heterogeneity in living organisms. In order to contribute to endothelial heterogeneity, signaling pathways should satisfy certain criteria. For instance, signaling pathways that enrich endothelial heterogeneity should not provide essential functions for endothelial survival but rather function as "auxiliary" cues. In addition, such signaling should elicit its effects in a context-dependent manner. Therefore, signaling pathways, which provide non-essential roles and have been shown to elicit angiogenic responses from a selected subtype of ECs without affecting the viability of ECs, are likely to be instrumental in creating endothelial heterogeneity. Conversely, signaling pathways such as vascular endothelial growth factor-A (VEGF-A) signaling, which are indispensable for the survival of ECs and elicit robust responses from all subtypes of ECs (Byrne et al., 2005), are less likely to contribute to endothelial heterogeneity. 
As one of the archetypal receptor-ligand-mediated signaling pathways, bone morphogenetic protein (BMP) signaling has gained increasing importance in the development and homeostasis of the vascular system. Its ability to selectively activate ECs in a context-dependent manner without influencing the survival of ECs (Cunha et al., 2017; Goumans et al., 2018) satisfies the aforementioned criteria of a signaling pathway of which function is important for establishing and promoting endothelial heterogeneity. Belonging to the transforming growth factor- $\beta$ (TGF- $\beta$ ) family, BMP signaling forms the largest subgroup with more than a dozen ligands and four BMP-specific type I (Miyazono et al., 2010). The canonical signaling pathway is initiated by a dimeric ligand binding to its heterotetrameric receptor complex, consisting of two type I and two type II receptors, leading to the phosphorylation of the receptors (Figure 1A). The activated receptors, in turn, phosphorylate downstream target SMAD1/5/8, which translocates into the nucleus in association with SMAD4 to modify transcriptomic profiles. In addition, it has been shown that BMP signaling could activate mitogen-activated protein kinase (MAPK) pathway in a context-dependent manner (Massague, 2003).

To better understand how BMP signaling modulates endothelial heterogeneity, it is essential to understand how BMP signaling functions within ECs. However, a simplified schematic diagram fails to capture the complex molecular landscape of BMP signaling, since distinct expression patterns of individual BMP signaling components result in diverse contextdependent outcomes (Seeherman et al., 2019). In addition, certain combinations of ligands and receptors differently regulate signaling, generating diverse cellular responses (Antebi et al., 2017). Moreover, numerous factors modulate the amplitude and duration of BMP signaling to further increase the complexity of BMP signaling. In this review, we provide a general overview of how BMP signaling functions in ECs and contributes to endothelial heterogeneity. We summarize how distinct responses toward BMP stimulation within subtypes of ECs contribute to endothelial heterogeneity.

\section{ENDOTHELIAL HETEROGENEITY AND BMP SIGNALING}

Bone morphogenetic protein signaling appears to function as a critical factor that enhances endothelial heterogeneity. During embryogenesis, it has been shown that BMP signaling promotes the specification of venous ECs (Neal et al., 2019), therefore, sets apart arterial and venous fates, and modulates the initial setup of endothelial heterogeneity. Lack of Alk3 within naïve ECs led to the failure of venous specific marker expression in presumptive venous ECs (Neal et al., 2019). In sprouting angiogenesis, BMP signaling has been shown to modulate dynamics between tip and stalk cell fates during sprouting angiogenesis (Moya et al., 2012), thereby enriching the endothelial heterogeneity.

Based on the subtypes, cellular responses toward BMP stimulation appear to be distinct among ECs which could further reinforce the endothelial heterogeneity. For instance, BMP signaling elicits distinct outcomes in blood ECs (BECs) and lymphatic ECs (LECs), the two major subtypes of ECs (Wiley and Jin, 2011; Coso et al., 2014). Therefore, it appears as if the responses toward BMP ligands in LECs are opposite to those in BECs. Given that the majority of LECs emerge via transdifferentiation of BECs, primarily venous in nature (Oliver and Srinivasan, 2010), it appears that the propensity to respond to a specific BMP ligand alters as a part of the transdifferentiation program. While it is apparent that BECs and LECs distinctively respond to BMP stimulation, it is largely unknown which factors are responsible for creating subtype-specific responses toward BMP stimulation. Considering this built-in redundancy of BMP signaling at the level of ligands, receptors, as well as effectors, it is tempting to speculate that these two subtypes of ECs may utilize pre-dominant receptors and effectors, which could facilitate subtype-specific responses. Recent analyses on the expression of BMP signaling components corroborate this idea (Yoshimatsu et al., 2013; Takeda et al., 2019).

Even within BECs, it has been shown that the responsiveness toward BMP signaling also varies between arterial and venous ECs. For instance, we and others have shown that proangiogenic BMP signaling could selectively induce angiogenic responses in venous ECs without affecting arterial ECs (Wiley et al., 2011; Kashiwada et al., 2015). Together, these studies highlight the innate differences of arterial and venous ECs in BMP responsiveness, which appears to modulate sprouting angiogenesis, potentially in conjunction with Notch and VEGFA signaling. For instance, Notch signaling has been shown to interact with BMP signaling to orchestrate the intricate process of sprouting angiogenesis (Moya et al., 2012). Moreover, Notch renders the responsiveness of ECs toward pro-angiogenic BMP stimuli, BMP2 and BMP6, by regulating the expression of SMAD6, which ultimately contributes to the phosphorylation of SMAD1/5 and a tip cell phenotype (Mouillesseaux et al., 2016). Recent findings also implicated synergistic effects of BMP signaling and VEGF signaling on tip cell-associated markers VEGFR2 and DLL4 (Pulkkinen et al., 2020). Furthermore, Notch signaling also appears to influence BMP signaling at the effector level since the expression of Herp2 in ECs is co-modulated by Notch and BMP6 signaling (Itoh et al., 2004). Taken together, these studies reiterate the significance of BMP signaling and its mutual interaction with other signaling pathways in regulating endothelial behavior during angiogenesis.

\section{FACTORS THAT MODIFY CELLULAR OUTCOMES OF BMP SIGNALING}

Bone morphogenetic protein signaling seems to be highly context-dependent, eliciting opposite outcomes in similar cell types (Abe et al., 2000; Shu et al., 2011). It appears that multiple layers of modulation collectively shape the signaling landscape of BMP ligands: Ligand-receptor interaction in diverse combinations which can be further modulated by agonists and antagonists, mechanical forces which are sensed by the cell and transmitted into biochemical cues, and post-transcriptional and post-translational regulations which provide fine-tuning for the signaling pathway, collectively formulate outcomes of BMP 


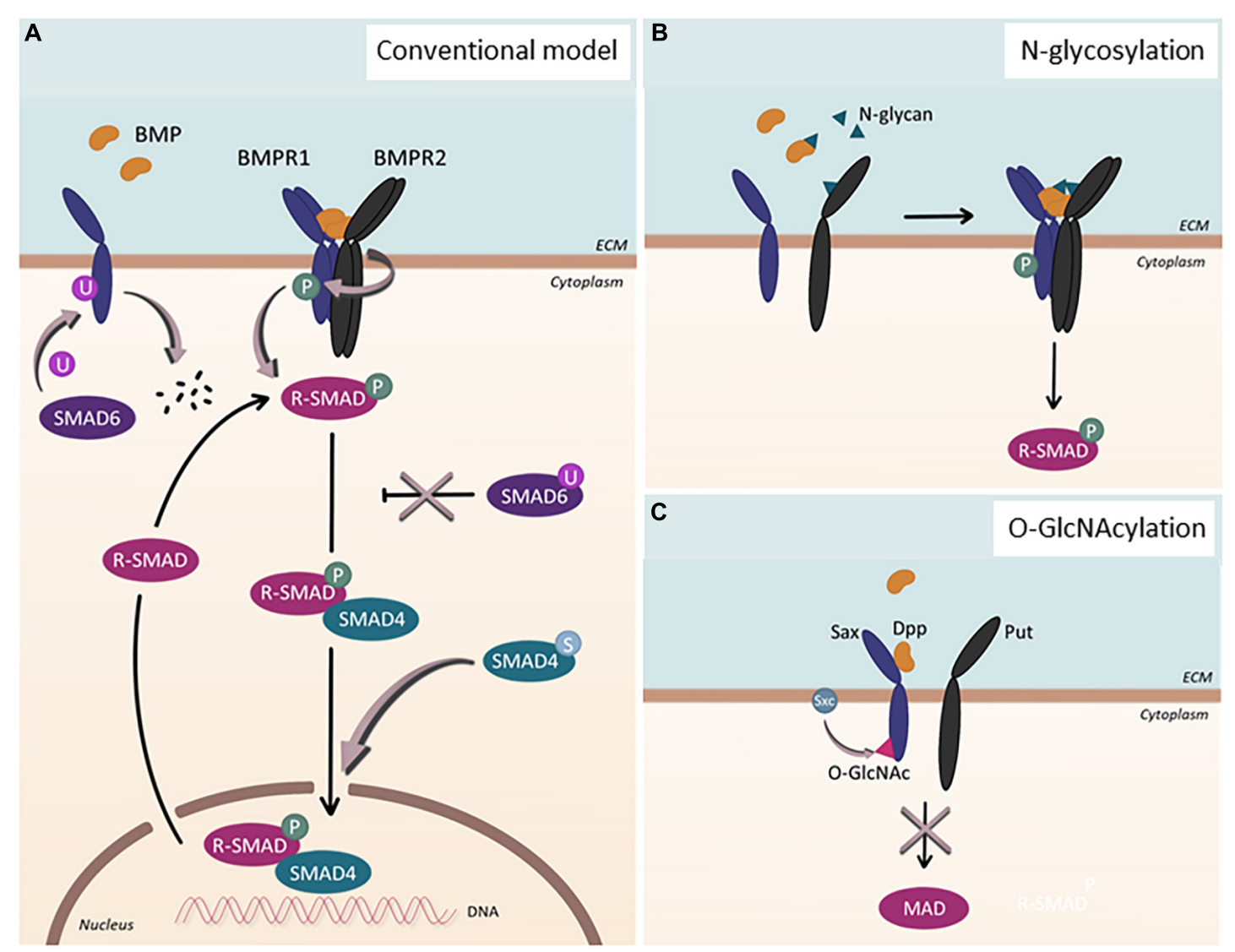

FIGURE 1 | Post-translational modification of BMP signaling components. (A) Conventional model of BMP signaling pathway. Upon BMP ligand binding, BMP type 1 receptor (BMPR1) is phosphorylated. Subsequently, R-SMADs, SMAD1/5/8, become phosphorylated and, together with SMAD4, localize into the nucleus to regulate gene transcription. This process can be inhibited by SMAD6. Additional post-translational modifications affect the signaling pathway in various ways: SMAD6 can regulate BMPR1 by facilitating its ubiquitination and subsequent degradation. Upon ubiquitination of SMAD6, SMAD6 loses its ability to inhibit the BMP signaling cascade, which ultimately leads to upregulation of the signaling pathway. When SMAD4 undergoes sumoylation, nuclear accumulation of the protein is enhanced. (B) N-glycosylation. N-glycans can bind to BMP ligands as well as to BMP type 2 receptors (BMPR2), enabling proper folding and binding of the proteins. (C) O-GlcNAcylation. In Drosophila, Sxc facilitates O-GlcNAcylation of Sax, the ortholog for human ALK2, resulting in the attenuation of the signaling pathway.

signaling with a remarkable degree of flexibility and versatility. Only now, we begin to understand the influence of these factors in BMP signaling.

\section{Promiscuity of Ligand-Receptor Interaction}

As in other signaling cascades, BMP signaling features a multitude of ligands and receptors, which associate and communicate with each other in diverse ways. However, the multiplicity of these components is not employed equally; most of them exhibit redundant functions. Previous works have shown that a multitude of BMP ligands binds to the same receptor (Mueller and Nickel, 2012) with different affinities (Seeherman et al., 2019). However, there are practical limitations in determining the ligand-receptor promiscuity in living organisms. To circumvent these hurdles, Antebi et al. (2017) resorted to mathematical modeling. By elegantly demonstrating the ligand-receptor promiscuity and the complex reciprocities between its signaling components, they suggested that the redundancy of BMP signaling components might manifest specific signaling-processing capabilities. While this needs to be validated in vivo, computational analyses revealed that cells distinguish distinct signaling environments, such as the concentration of ligands and differences in ligand-receptor complexes, to respond to BMP stimulation. Interestingly, inside the signaling-receiving cells, the canonical downstream target SMAD1/5/8 is activated regardless of the signaling-conferring ligand-receptor complex, suggesting the possibility that signaling-receiving cells are only capable of perceiving the sum of BMP ligand stimulation (David and Massague, 2018). This scenario, which is feasible in theory, certainly contradicts the prevailing idea that each BMP ligand retains its unique role in vivo (Wang et al., 2014). Therefore, further analyses are warranted to fully understand how the promiscuity of ligand-receptor interaction affects the context-dependent and heterogeneous signaling outcomes of BMP signaling. 


\section{Environmental Factors}

It has been shown that mechanical forces affect the outcomes of BMP signaling in a number of cell types (Sedlmeier and Sleeman, 2017). For instance, abrogation of $\alpha 5 \beta 1$ integrin in vertebrate embryos substantially decreases the response of chondrocytes toward BMP stimulation (Garciadiego-Cazares et al., 2004, 2015). ECs provide another example of responsiveness toward BMP stimulation which is modulated by environmental factors. Previously, shear stress, the mechanical force created by laminar flow, has been implicated in regulating BMP signaling in ECs (Min and Schwartz, 2019; Hiepen et al., 2020). Upon exposure to shear stress, SMAD1/5/8 becomes phosphorylated in both BECs and LECs, dependent on the type and magnitude of shear stress. While turbulent shear stress induced by low oscillatory flow promotes EC proliferation and leads to SMAD1/5/8 phosphorylation (Zhou et al., 2012), laminar shear stress contributes to the quiescence of ECs through the BMP9ALK1/ENG-SMAD1/5/8 axis (Baeyens et al., 2016), potentially going through the primary cilia (Vion et al., 2018). Interestingly, SMAD1 was most strongly affected by laminar shear stress, whereas SMAD5 and SMAD8 were less responsive (Baeyens et al., 2016). Moreover, the depletion of SMAD4 in human coronary artery ECs impaired the alignment of ECs to blood flow and led to an increased diameter of coronary arteries in developing mice (Poduri et al., 2017). Therefore, it appears that the types of flow, potentially modulating the activity of distinct SMADs, influence outcomes of BMP signaling in ECs. In addition to mechanical forces, recent studies reported hypoxia as one of the potential modulators for BMP signaling. Under hypoxic conditions, differential expression of BMP ligands could be observed in comparison to normoxic conditions (Pulkkinen et al., 2021). Moreover, BMP signaling could also attenuate hypoxic responses in ECs through the ALK1/SMAD/ATOH8 axis, ultimately impeding the development of pulmonary arterial hypertension (PAH) (Morikawa et al., 2019).

\section{Transcriptional and Post-transcriptional Regulation}

The responses toward BMP stimulation are further regulated by modifying BMP signaling components. For instance, the transcriptional efficacy of BMP signaling target genes can be modulated by epigenetic factors and other transcriptional co-factors. SMAD1 interacts with p300/CREB-binding protein (CBP) in vitro and in vivo, which enhances upon phosphorylation of SMAD1 (Nakashima et al., 1999; Pearson et al., 1999). In addition, SMAD1 can form a ternary complex with Notch intracellular domain in the presence of p300/CBP and P/CAF to augment transcriptional activation of Notch target genes (Takizawa et al., 2003). Moreover, chromatin immunoprecipitation analysis in ECs and pulmonary arterial smooth muscle cells revealed that SMAD1/5 preferentially binds to the GC-rich SMAD binding element outside the promoter of known genes, which appears to be mediated by epigenetic factors (Morikawa et al., 2011). Furthermore, responses toward BMP signaling are modulated by posttranscriptional regulation. For instance, numerous miRNAs are involved in BMP signaling-regulated processes (Hata and Kang, 2015). Recent studies provided persuasive evidence of the role of miRNAs in modulating BMP signaling (Dunworth et al., 2014). Therefore, it is apparent that transcriptional as well as posttranscriptional regulation of BMP signaling components could alter the landscape of BMP signaling.

\section{Post-translational Regulation}

Post-translational modifications (PTMs) have been shown to contribute to the extensive versatility and complexity of signaling pathways in eukaryotic cells. Perturbations of PTMs have been linked to various diseases, illustrating the significance of PTMs in maintaining cellular homeostasis (Li et al., 2010; Karve and Cheema, 2011). While PTMs in the TGF- $\beta$ signaling pathway (Xu et al., 2012) have been studied intensively, far less is known about them in BMP signaling. The best-studied PTM in the BMP signaling is phosphorylation, the reversible attachment of a phosphoryl group to its receptors and downstream targets (Figure 1A). Upon ligand binding, successive phosphorylation ensues (Nickel and Mueller, 2019); the constitutively active BMPR2 phosphorylates the GS-domain of BMPR1s (Wrana et al., 1994), which, in turn, phosphorylate the SSXS motif of SMAD1/5/8 (Chen et al., 1997; Kretzschmar et al., 1997; Suzuki et al., 1997).

In addition to phosphorylation, ubiquitination and sumoylation, both of which are reversible PTM, have been shown to modulate the context of BMP signaling (Hershko and Ciechanover, 1998) (Figure 1A). The primary target of ubiquitination within BMP signaling appears to be SMAD1/5 (Zhu et al., 1999), though other components of BMP signaling, including SMAD6 and ACVR1/ALK2, could also undergo ubiquitination (Zhang et al., 2013; Herhaus et al., 2014; Seo et al., 2019). In addition, several studies have shown that SMAD4 could be sumoylated, which promotes SMAD4 accumulation into the nucleus and prolongs BMP signaling (Lin et al., 2003). Considering the complex interplay between ubiquitination and sumoylation (Liebelt and Vertegaal, 2016), balance between these PTMs may provide additional regulatory input for BMP signaling, which, however, requires further investigation.

Beyond these well-studied PTMs, other less established protein modifications have been acknowledged to be of great significance in modulating BMP signaling outcomes, including methylation, acetylation, O-GlcNAcylation, and acylation (Figures 1B,C). For instance, O-GlcNAcylation, which is the addition of a single $\mathrm{O}$-linked $\mathrm{N}$-acetyl-glucosamine $(\mathrm{O}$ GlcNAc) moiety to target proteins, has been shown to fine-tune Drosophila BMP type I receptor Saxophone (Sax), an ortholog for human ALK2 (Moulton et al., 2020). In addition, it has been reported that a number of BMP ligands and BMPR2 undergo N-linked glycosylation, the addition of glycan to the target proteins (Garrigue-Antar et al., 2002; Hang et al., 2014; Negreiros et al., 2018). Interestingly, the $\mathrm{N}$-glycosylation consensus of BMPR2 was positioned at a site that is mutated in heritable PAH patients (Pfarr et al., 2011; Lowery et al., 2014), alluding to the importance of this PTM for modulating the activity of BMP signaling. Increasing evidence also suggests 


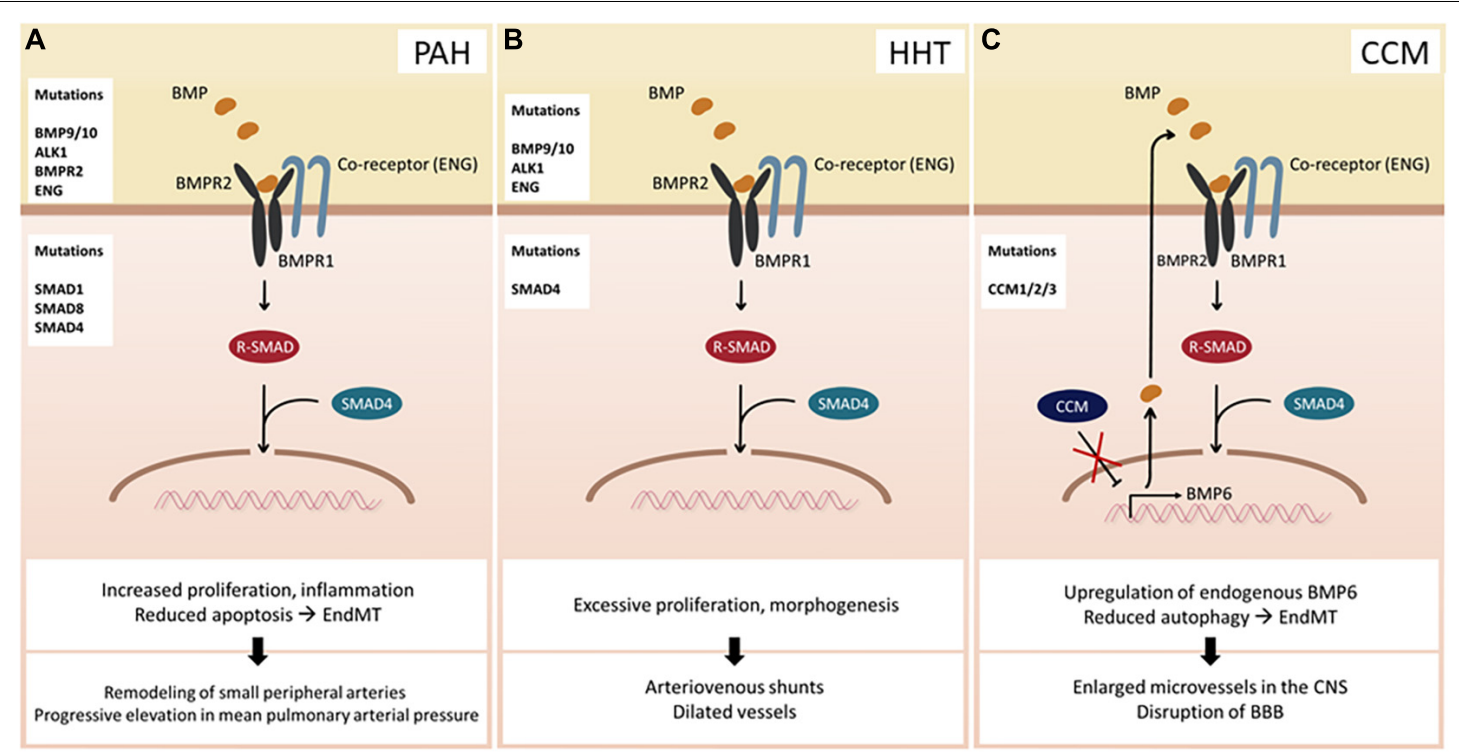

FIGURE 2 | Consequences of BMP signaling dysfunction. (A) Pulmonary arterial hypertension (PAH) can occur due to mutations in BMP ligands, receptors, co-receptors, and SMAD proteins. (B) Hereditary hemorrhagic telangiectasia (HHT) arises upon mutation of BMP9/10, ALK1, ENG, or SMAD4. (C) Cerebral cavernous malformation (CCM) develops when one of the CCM proteins is mutated. Hence, transcriptional activity of BMP6 increases leading to an enhanced BMP signaling. Abbreviations: CNS, central nervous system; BBB, blood-brain barrier.

the regulation of BMP signaling by methylation by which the inhibitory effect of Smad6 could be ensured (Xu et al., 2013; Wu et al., 2021).

\section{THE ROLE OF BMP SIGNALING IN ENDOTHELIAL DYSFUNCTION}

Numerous studies have suggested that dysregulation of BMP signaling in ECs could lead to various diseases. For instance, mutations in BMPR2 predispose to the onset of PAH (Figure 2A), a rare chronic disease characterized by an increase in mean pulmonary arterial pressure, which eventually leads to failure of the right ventricle (Dunmore et al., 2021). Recent studies using next-generation sequencing (NGS) technology have identified more than 800 mutations, including 486 distinct, non-recurrent variants, many of which affect BMP signaling in ECs (Southgate et al., 2020). Moreover, other BMP-related genes have also been implicated with PAH (Graf et al., 2018). Another well-established disease associated with dysfunctional BMP signaling in ECs is hereditary hemorrhagic telangiectasia (HHT) (Figure 2B) and cerebral cavernous malformation (CCM) (Figure 2C), both of which are autosomal dominant disorders. The clinical hallmarks of HHT are dilated vessels and arteriovenous shunts, which are prone to rupture. To date, mutations in a number of BMP signaling components, including Endoglin, ALK1, SMAD4, and more recently, BMP9 (McAllister et al., 1994; Johnson et al., 1996), have been identified in a smaller group of patients. However, the underlying molecular basis of HHT has not been fully elucidated. CCM is another hereditary condition that leads to enlarged microvessels in the central nervous system, which are susceptible to hemorrhage due to loss-of-function mutations in one of the three autosomal genes collectively known as the CCMs (Labauge et al., 2007). Deletion of any of the three genes results in increased synthesis of endogenous BMP6, which, in part, is promoted by KLF4 (Cuttano et al., 2016). Moreover, endothelial-specific deletion of $C \mathrm{~cm} 1$ and $\mathrm{Ccm} 3$ in mice induces endothelial to mesenchymal transition (EndMT), which contributes to the development of vascular lesions (Maddaluno et al., 2013; Malinverno et al., 2019), hinting that dysregulation of BMP signaling plays a key role in the progression of the CCMs. It is worth noting that only a subset of ECs appears to be affected by the pathological conditions caused by dysregulation of BMP signaling. For instance, arteriovenous shunts formed in HHT patients are initiated by a subset of venous ECs, which undergo excessive proliferation and morphogenesis (Brinjikji et al., 2015). In addition, while $\mathrm{PAH}$ promotes EndMT, only a subset of ECs in PAH patients transforms into vascular smooth muscle cells (Ranchoux et al., 2015). Therefore, it is fathomable that the effects of dysregulated BMP signaling on ECs are also highly heterogeneous, reminiscent of normal physiological responses toward BMP signaling.

\section{PERSPECTIVES}

As we obtain comprehensive knowledge on the role of BMP signaling in endothelial heterogeneity, we are confronted with a plethora of enigmas. Increasing evidence indicates that the complexity of BMP signaling dynamics provides essential regulation on endothelial plasticity. Emerging reports have identified novel fine-tuning regulatory mechanisms for BMP 
signaling. While their functions remain largely unknown in the endothelium, given the ubiquitous expression of these regulators, it is plausible that BMP signaling in ECs is similarly modulated. Since the role of BMP signaling in endothelial heterogeneity is still in its infancy, it will be of great importance to elucidate distinct regulatory mechanisms and more importantly its impact on the endothelial phenotype, which ultimately will lead to distinct physiological responses in the body. The plethora of regulatory possibilities provide an additional dimension for regulating distinct $\mathrm{BMP}$ signaling components and therefore further enrich the impact of the BMP signaling on endothelial heterogeneity. Not yet identified environmental factors, as well as various PTMs, might give us answers to yet unsolved enigmas and offer novel strategies to overcome limitations faced so far. Therefore, further investigations will provide insights into how such a conceptually simple signaling cascade can give rise to exquisite plasticity and versatility. Moreover, the availability of novel techniques, such as NGS, single-cell analysis, and bioinformatics, will refine our understanding of endothelial dysfunctions and concomitant diseases and ultimately contribute

\section{REFERENCES}

Abe, E., Yamamoto, M., Taguchi, Y., Lecka-Czernik, B., O’Brien, C. A., Economides, A. N., et al. (2000). Essential requirement of BMPs-2/4 for both osteoblast and osteoclast formation in murine bone marrow cultures from adult mice: antagonism by noggin. J. Bone Miner. Res. 15, 663-673. doi: 10.1359/jbmr. 2000.15.4.663

Aird, W. C. (2003). Endothelial cell heterogeneity. Crit. Care Med. 31, S221-S230. doi: 10.1097/01.CCM.0000057847.32590.C1

Antebi, Y. E., Linton, J. M., Klumpe, H., Bintu, B., Gong, M., Su, C., et al. (2017). Combinatorial signal perception in the BMP pathway. Cell 170, 1184-1196. doi: 10.1016/j.cell.2017.08.015

Baeyens, N., Larrivee, B., Ola, R., Hayward-Piatkowskyi, B., Dubrac, A., Huang, B., et al. (2016). Defective fluid shear stress mechanotransduction mediates hereditary hemorrhagic telangiectasia. J. Cell Biol. 214, 807-816. doi: 10.1083/ jcb.201603106

Bautch, V. L., and Caron, K. M. (2015). Blood and lymphatic vessel formation. Cold Spring Harb. Perspect. Biol. 7:a008268. doi: 10.1101/cshperspect.a008268

Brinjikji, W., Iyer, V. N., Sorenson, T., and Lanzino, G. (2015). Cerebrovascular manifestations of hereditary hemorrhagic telangiectasia. Stroke 46, 3329-3337. doi: 10.1161/STROKEAHA.115.010984

Byrne, A. M., Bouchier-Hayes, D. J., and Harmey, J. H. (2005). Angiogenic and cell survival functions of vascular endothelial growth factor (VEGF). J. Cell. Mol. Med. 9, 777-794. doi: 10.1111/j.1582-4934.2005.tb00379.x

Chen, Y., Bhushan, A., and Vale, W. (1997). Smad8 mediates the signaling of the ALK-2 [corrected] receptor serine kinase. Proc. Natl. Acad. Sci. U.S.A. 94, 12938-12943. doi: 10.1073/pnas.94.24.12938

Chi, J. T., Chang, H. Y., Haraldsen, G., Jahnsen, F. L., Troyanskaya, O. G., Chang, D. S., et al. (2003). Endothelial cell diversity revealed by global expression profiling. Proc. Natl. Acad. Sci. U.S.A. 100, 10623-10628. doi: 10.1073/pnas. 1434429100

Coso, S., Bovay, E., and Petrova, T. V. (2014). Pressing the right buttons: signaling in lymphangiogenesis. Blood 123, 2614-2624. doi: 10.1182/blood-2013-12297317

Cunha, S. I., Magnusson, P. U., Dejana, E., and Lampugnani, M. G. (2017). Deregulated TGF-beta/BMP signaling in vascular malformations. Circ. Res. 121, 981-999. doi: 10.1161/CIRCRESAHA.117.309930

Cuttano, R., Rudini, N., Bravi, L., Corada, M., Giampietro, C., Papa, E., et al. (2016). KLF4 is a key determinant in the development and progression of cerebral cavernous malformations. EMBO Mol. Med. 8, 6-24. doi: 10.15252/emmm. 201505433 to the development of new therapeutic interventions for various diseases by fully harnessing the heterogeneity and contextdependent properties of BMP signaling.

\section{AUTHOR CONTRIBUTIONS}

All authors wrote and edited the manuscript.

\section{FUNDING}

This work was supported by grants from the National Research Foundation of Korea (NRF-2016R1A5A1007318 and NRF2019R1A2C2088125) to S-WJ.

\section{ACKNOWLEDGMENTS}

We thank the member of Jin laboratory for helpful discussion and critical reading of the manuscript.

David, C. J., and Massague, J. (2018). Contextual determinants of TGFbeta action in development, immunity and cancer. Nat. Rev. Mol. Cell. Biol. 19, 419-435. doi: 10.1038/s41580-018-0007-0

Dunmore, B. J., Jones, R. J., Toshner, M. R., Upton, P. D., and Morrell, N. W. (2021). Approaches to treat pulmonary arterial hypertension by targeting bmpr2 - from cell membrane to nucleus. Cardiovasc. Res. cvaa350. doi: 10.1093/ cvr/cvaa350 [Epub ahead of print].

Dunworth, W. P., Cardona-Costa, J., Bozkulak, E. C., Kim, J. D., Meadows, S., Fischer, J. C., et al. (2014). Bone morphogenetic protein 2 signaling negatively modulates lymphatic development in vertebrate embryos. Circ. Res. 114, 56-66. doi: 10.1161/CIRCRESAHA.114.302452

Garciadiego-Cazares, D., Aguirre-Sanchez, H. I., Abarca-Buis, R. F., Kouri, J. B., Velasquillo, C., and Ibarra, C. (2015). Regulation of alpha5 and alphaV integrin expression by GDF-5 and BMP-7 in chondrocyte differentiation and osteoarthritis. PLoS One 10:e127166. doi: 10.1371/journal.pone.0127166

Garciadiego-Cazares, D., Rosales, C., Katoh, M., and Chimal-Monroy, J. (2004). Coordination of chondrocyte differentiation and joint formation by alpha5betal integrin in the developing appendicular skeleton. Development 131, 4735-4742. doi: 10.1242/dev.01345

Garrigue-Antar, L., Hartigan, N., and Kadler, K. E. (2002). Post-translational modification of bone morphogenetic protein-1 is required for secretion and stability of the protein. J. Biol. Chem. 277, 43327-43334. doi: 10.1074/jbc. M207342200

Goumans, M. J., Zwijsen, A., Ten Dijke, P., and Bailly, S. (2018). Bone morphogenetic proteins in vascular homeostasis and disease. Cold Spring Harb. Perspect. Biol. 10:a031989. doi: 10.1101/cshperspect.a031989

Graf, S., Haimel, M., Bleda, M., Hadinnapola, C., Southgate, L., Li, W., et al. (2018). Identification of rare sequence variation underlying heritable pulmonary arterial hypertension. Nat. Commun. 9:1416. doi: 10.1038/s41467-018-0 3672-4

Hang, Q., Zhou, Y., Hou, S., Zhang, D., Yang, X., Chen, J., et al. (2014). Asparaginelinked glycosylation of bone morphogenetic protein-2 is required for secretion and osteoblast differentiation. Glycobiology 24, 292-304. doi: 10.1093/glycob/ cwt110

Hata, A., and Kang, H. (2015). Functions of the bone morphogenetic protein signaling pathway through microRNAs (review). Int. J. Mol. Med. 35, 563-568. doi: 10.3892/ijmm.2015.2060

Herhaus, L., Al-Salihi, M. A., Dingwell, K. S., Cummins, T. D., Wasmus, L., Vogt, J., et al. (2014). USP15 targets ALK3/BMPR1A for deubiquitylation to enhance bone morphogenetic protein signalling. Open Biol. 4:140065. doi: 10.1098/rsob. 140065 
Hershko, A., and Ciechanover, A. (1998). The ubiquitin system. Annu. Rev. Biochem. 67, 425-479. doi: 10.1146/annurev.biochem.67.1.425

Hiepen, C., Mendez, P. L., and Knaus, P. (2020). It takes two to tango: endothelial TGFbeta/BMP signaling crosstalk with mechanobiology. Cells 9:1965. doi: 10. 3390/cells9091965

Itoh, F., Itoh, S., Goumans, M. J., Valdimarsdottir, G., Iso, T., Dotto, G. P., et al. (2004). Synergy and antagonism between Notch and BMP receptor signaling pathways in endothelial cells. EMBO J. 23, 541-551. doi: 10.1038/sj.emboj. 7600065

Johnson, D. W., Berg, J. N., Baldwin, M. A., Gallione, C. J., Marondel, I., Yoon, S. J., et al. (1996). Mutations in the activin receptor-like kinase 1 gene in hereditary haemorrhagic telangiectasia type 2. Nat. Genet. 13, 189-195. doi: 10.1038/ng0696-189

Kalucka, J., de Rooij, L., Goveia, J., Rohlenova, K., Dumas, S. J., Meta, E., et al. (2020). Single-cell transcriptome atlas of murine endothelial cells. Cell 180:e720. doi: $10.1016 /$ j.cell.2020.01.015

Karve, T. M., and Cheema, A. K. (2011). Small changes huge impact: the role of protein posttranslational modifications in cellular homeostasis and disease. J. Amino Acids 2011:207691. doi: 10.4061/2011/207691

Kashiwada, T., Fukuhara, S., Terai, K., Tanaka, T., Wakayama, Y., Ando, K., et al. (2015). Beta-Catenin-dependent transcription is central to Bmp-mediated formation of venous vessels. Development 142, 497-509. doi: 10.1242/dev. 115576

Kretzschmar, M., Liu, F., Hata, A., Doody, J., and Massague, J. (1997). The TGF-beta family mediator Smad1 is phosphorylated directly and activated functionally by the BMP receptor kinase. Genes Dev. 11, 984-995. doi: 10.1101/ gad.11.8.984

Labauge, P., Denier, C., Bergametti, F., and Tournier-Lasserve, E. (2007). Genetics of cavernous angiomas. Lancet Neurol. 6, 237-244. doi: 10.1016/S14744422(07)70053-4

Li, S., Iakoucheva, L. M., Mooney, S. D., and Radivojac, P. (2010). Loss of posttranslational modification sites in disease. Pac. Symp. Biocomput. 15, 337-347. doi: 10.1142/9789814295291_0036

Liebelt, F., and Vertegaal, A. C. (2016). Ubiquitin-dependent and independent roles of SUMO in proteostasis. Am. J. Physiol. Cell. Physiol. 311, C284-C296. doi: 10.1152/ajpcell.00091.2016

Lin, X., Liang, M., Liang, Y. Y., Brunicardi, F. C., and Feng, X. H. (2003). SUMO-1/Ubc9 promotes nuclear accumulation and metabolic stability of tumor suppressor Smad4. J. Biol. Chem. 278, 31043-31048. doi: 10.1074/jbc. C300112200

Lowery, J. W., Amich, J. M., Andonian, A., and Rosen, V. (2014). N-linked glycosylation of the bone morphogenetic protein receptor type 2 (BMPR2) enhances ligand binding. Cell Mol. Life Sci. 71, 3165-3172. doi: 10.1007/s00018013-1541-8

Maddaluno, L., Rudini, N., Cuttano, R., Bravi, L., Giampietro, C., Corada, M., et al. (2013). EndMT contributes to the onset and progression of cerebral cavernous malformations. Nature 498, 492-496. doi: 10.1038/nature 12207

Malinverno, M., Maderna, C., Abu Taha, A., Corada, M., Orsenigo, F., Valentino, M., et al. (2019). Endothelial cell clonal expansion in the development of cerebral cavernous malformations. Nat. Commun. 10:2761. doi: 10.1038/ s41467-019-10707-x

Massague, J. (2003). Integration of Smad and MAPK pathways: a link and a linker revisited. Genes Dev. 17, 2993-2997. doi: 10.1101/gad.1167003

McAllister, K. A., Grogg, K. M., Johnson, D. W., Gallione, C. J., Baldwin, M. A., Jackson, C. E., et al. (1994). Endoglin, a TGF-beta binding protein of endothelial cells, is the gene for hereditary haemorrhagic telangiectasia type 1. Nat. Genet. 8, 345-351. doi: 10.1038/ng1294-345

Min, E., and Schwartz, M. A. (2019). Translocating transcription factors in fluid shear stress-mediated vascular remodeling and disease. Exp. Cell Res. 376, 92-97. doi: 10.1016/j.yexcr.2019.01.005

Miyazono, K., Kamiya, Y., and Morikawa, M. (2010). Bone morphogenetic protein receptors and signal transduction. J. Biochem. 147, 35-51. doi: 10.1093/jb/ mvp148

Morikawa, M., Koinuma, D., Tsutsumi, S., Vasilaki, E., Kanki, Y., Heldin, C. H., et al. (2011). ChIP-seq reveals cell type-specific binding patterns of BMPspecific Smads and a novel binding motif. Nucleic Acids Res. 39, 8712-8727. doi: $10.1093 /$ nar/gkr572
Morikawa, M., Mitani, Y., Holmborn, K., Kato, T., Koinuma, D., Maruyama, J., et al. (2019). The ALK-1/SMAD/ATOH8 axis attenuates hypoxic responses and protects against the development of pulmonary arterial hypertension. Sci. Signal. 12:eaay4430. doi: 10.1126/scisignal.aay4430

Mouillesseaux, K. P., Wiley, D. S., Saunders, L. M., Wylie, L. A., Kushner, E. J., Chong, D. C., et al. (2016). Notch regulates BMP responsiveness and lateral branching in vessel networks via SMAD6. Nat. Commun. 7:13247. doi: 10.1038/ ncomms 13247

Moulton, M. J., Humphreys, G. B., Kim, A., and Letsou, A. (2020). OGlcNAcylation dampens Dpp/BMP signaling to ensure proper drosophila embryonic development. Dev. Cell 53:e333. doi: 10.1016/j.devcel.2020. 04.001

Moya, I. M., Umans, L., Maas, E., Pereira, P. N., Beets, K., Francis, A., et al. (2012). Stalk cell phenotype depends on integration of Notch and Smad1/5 signaling cascades. Dev. Cell 22, 501-514. doi: 10.1016/j.devcel.2012.01.007

Mueller, T. D., and Nickel, J. (2012). Promiscuity and specificity in BMP receptor activation. FEBS Lett. 586, 1846-1859. doi: 10.1016/j.febslet.2012.02.043

Nakashima, K., Wiese, S., Yanagisawa, M., Arakawa, H., Kimura, N., Hisatsune, T., et al. (1999). Developmental requirement of gp130 signaling in neuronal survival and astrocyte differentiation. J. Neurosci. 19, 5429-5434. doi: 10.1523/ jneurosci.19-13-05429.1999

Neal, A., Nornes, S., Payne, S., Wallace, M. D., Fritzsche, M., Louphrasitthiphol, P., et al. (2019). Venous identity requires BMP signalling through ALK3. Nat. Commun. 10:453. doi: 10.1038/s41467-019-08315-w

Negreiros, E., Herszterg, S., Kang, K. H., Camara, A., Dias, W. B., Carneiro, K., et al. (2018). N-linked glycosylation restricts the function of Short gastrulation to bind and shuttle BMPs. Development 145:dev167338. doi: 10.1242/dev.167338

Nickel, J., and Mueller, T. D. (2019). Specification of BMP signaling. Cells 8:1579. doi: $10.3390 /$ cells8121579

Nolan, D. J., Ginsberg, M., Israely, E., Palikuqi, B., Poulos, M. G., James, D., et al. (2013). Molecular signatures of tissue-specific microvascular endothelial cell heterogeneity in organ maintenance and regeneration. Dev. Cell 26, 204-219. doi: 10.1016/j.devcel.2013.06.017

Oliver, G., and Srinivasan, R. S. (2010). Endothelial cell plasticity: how to become and remain a lymphatic endothelial cell. Development 137, 363-372. doi: 10. 1242/dev.035360

Pak, B., Schmitt, C. E., Choi, W., Kim, J. D., Han, O., Alsio, J., et al. (2020). Analyses of avascular mutants reveal unique transcriptomic signature of nonconventional endothelial cells. Front. Cell Dev. Biol. 8:589717. doi: 10.3389/fcell. 2020.589717

Pearson, K. L., Hunter, T., and Janknecht, R. (1999). Activation of Smad1-mediated transcription by p300/CBP. Biochim. Biophys. Acta 1489, 354-364. doi: 10.1016/ s0167-4781(99)00166-9

Pfarr, N., Szamalek-Hoegel, J., Fischer, C., Hinderhofer, K., Nagel, C., Ehlken, N., et al. (2011). Hemodynamic and clinical onset in patients with hereditary pulmonary arterial hypertension and BMPR2 mutations. Respir. Res. 12:99. doi: 10.1186/1465-9921-12-99

Poduri, A., Chang, A. H., Raftrey, B., Rhee, S., Van, M., and Red-Horse, K. (2017). Endothelial cells respond to the direction of mechanical stimuli through SMAD signaling to regulate coronary artery size. Development 144, 3241-3252. doi: 10.1242/dev.150904

Pulkkinen, H. H., Kiema, M., Lappalainen, J. P., Toropainen, A., Beter, M., Tirronen, A., et al. (2020). BMP6/TAZ-Hippo signaling modulates angiogenesis and endothelial cell response to VEGF. Angiogenesis 24, 129-144. doi: 10.1007/ s10456-020-09748-4

Pulkkinen, H. H., Kiema, M., Lappalainen, J. P., Toropainen, A., Beter, M., Tirronen, A., et al. (2021). BMP6/TAZ-Hippo signaling modulates angiogenesis and endothelial cell response to VEGF. Angiogenesis 24, 129-144.

Ranchoux, B., Antigny, F., Rucker-Martin, C., Hautefort, A., Pechoux, C., Bogaard, H. J., et al. (2015). Endothelial-to-mesenchymal transition in pulmonary hypertension. Circulation 131, 1006-1018. doi: 10.1161/CIRCULATIONAHA. 114.008750

Sailem, H. Z., and Al Haj Zen, A. (2020). Morphological landscape of endothelial cell networks reveals a functional role of glutamate receptors in angiogenesis. Sci. Rep. 10:13829. doi: 10.1038/s41598-020-70440-0

Sedlmeier, G., and Sleeman, J. P. (2017). Extracellular regulation of BMP signaling: welcome to the matrix. Biochem. Soc. Trans. 45, 173-181. doi: 10.1042/ BST20160263 
Seeherman, H. J., Berasi, S. P., Brown, C. T., Martinez, R. X., Juo, Z. S., Jelinsky, S., et al. (2019). A BMP/activin A chimera is superior to native BMPs and induces bone repair in nonhuman primates when delivered in a composite matrix. Sci. Transl. Med. 11:eaar4953. doi: 10.1126/scitranslmed.aar4953

Seo, D., Jung, S. M., Park, J. S., Lee, J., Ha, J., Kim, M., et al. (2019). The deubiquitinating enzyme PSMD14 facilitates tumor growth and chemoresistance through stabilizing the ALK2 receptor in the initiation of BMP6 signaling pathway. EBioMedicine 49, 55-71. doi: 10.1016/j.ebiom.2019.10.039

Shu, B., Zhang, M., Xie, R., Wang, M., Jin, H., Hou, W., et al. (2011). BMP2, but not BMP4, is crucial for chondrocyte proliferation and maturation during endochondral bone development. J. Cell. Sci. 124, 3428-3440. doi: 10.1242/jcs. 083659

Southgate, L., Machado, R. D., Graf, S., and Morrell, N. W. (2020). Molecular genetic framework underlying pulmonary arterial hypertension. Nat. Rev. Cardiol. 17, 85-95. doi: 10.1038/s41569-019-0242-x

Suzuki, A., Chang, C., Yingling, J. M., Wang, X. F., and Hemmati-Brivanlou, A. (1997). Smad5 induces ventral fates in Xenopus embryo. Dev. Biol. 184, 402-405. doi: 10.1006/dbio.1997.8548

Takeda, A., Hollmen, M., Dermadi, D., Pan, J., Brulois, K. F., Kaukonen, R., et al. (2019). Single-cell survey of human lymphatics unveils marked endothelial cell heterogeneity and mechanisms of homing for neutrophils. Immunity 51, 561-572. doi: 10.1016/j.immuni.2019.06.027

Takizawa, T., Ochiai, W., Nakashima, K., and Taga, T. (2003). Enhanced gene activation by Notch and BMP signaling cross-talk. Nucleic Acids Res. 31, 5723-5731. doi: 10.1093/nar/gkg778

Vion, A. C., Alt, S., Klaus-Bergmann, A., Szymborska, A., Zheng, T., Perovic, T., et al. (2018). Primary cilia sensitize endothelial cells to BMP and prevent excessive vascular regression. J. Cell. Biol. 217, 1651-1665. doi: 10.1083/jcb. 201706151

Wang, R. N., Green, J., Wang, Z., Deng, Y., Qiao, M., Peabody, M., et al. (2014). Bone morphogenetic protein (BMP) signaling in development and human diseases. Genes Dis. 1, 87-105. doi: 10.1016/j.gendis.2014.07.005

Wiley, D. M., and Jin, S. W. (2011). Bone Morphogenetic Protein functions as a context-dependent angiogenic cue in vertebrates. Semin. Cell Dev. Biol. 22, 1012-1018. doi: 10.1016/j.semcdb.2011.10.005

Wiley, D. M., Kim, J. D., Hao, J., Hong, C. C., Bautch, V. L., and Jin, S. W. (2011). Distinct signalling pathways regulate sprouting angiogenesis from the dorsal aorta and the axial vein. Nat. Cell Biol. 13, 686-692. doi: 10.1038/ncb2232
Wrana, J. L., Attisano, L., Wieser, R., Ventura, F., and Massague, J. (1994). Mechanism of activation of the TGF-beta receptor. Nature 370, 341-347. doi: 10.1038/370341a0

Wu, J., Chen, X., Sehgal, P., Zhang, T., Jackson-Weaver, O., Gou, Y., et al. (2021). Arginine methylation of R81 in Smad6 confines BMP-induced Smad1 signaling. J. Biol. Chem. 296:100496. doi: 10.1016/j.jbc.2021.100496

Xu, J., Wang, A. H., Oses-Prieto, J., Makhijani, K., Katsuno, Y., Pei, M., et al. (2013). Arginine methylation initiates BMP-induced smad signaling. Mol. Cell 51, 5-19. doi: 10.1016/j.molcel.2013.05.004

Xu, P., Liu, J., and Derynck, R. (2012). Post-translational regulation of TGF-beta receptor and Smad signaling. FEBS Lett. 586, 1871-1884. doi: 10.1016/j.febslet. 2012.05.010

Yoshimatsu, Y., Lee, Y. G., Akatsu, Y., Taguchi, L., Suzuki, H. I., Cunha, S. I., et al. (2013). Bone morphogenetic protein-9 inhibits lymphatic vessel formation via activin receptor-like kinase 1 during development and cancer progression. Proc. Natl. Acad. Sci. U.S.A. 110, 18940-18945. doi:10.1073/pnas.13104 79110

Zhang, X., Zhang, J., Bauer, A., Zhang, L., Selinger, D. W., Lu, C. X., et al. (2013). Fine-tuning BMP7 signalling in adipogenesis by UBE2O/E2-230K-mediated monoubiquitination of SMAD6. EMBO J. 32, 996-1007. doi: 10.1038/emboj. 2013.38

Zhou, J., Lee, P. L., Tsai, C. S., Lee, C. I., Yang, T. L., Chuang, H. S., et al. (2012). Force-specific activation of $S$ mad1/5 regulates vascular endothelial cell cycle progression in response to disturbed flow. Proc. Natl. Acad. Sci. U.S.A. 109, 7770-7775. doi: 10.1073/pnas.1205476109

Zhu, H., Kavsak, P., Abdollah, S., Wrana, J. L., and Thomsen, G. H. (1999). A SMAD ubiquitin ligase targets the BMP pathway and affects embryonic pattern formation. Nature 400, 687-693. doi: 10.1038/23293

Conflict of Interest: The authors declare that the research was conducted in the absence of any commercial or financial relationships that could be construed as a potential conflict of interest.

Copyright (c) 2021 Han, Pak and Jin. This is an open-access article distributed under the terms of the Creative Commons Attribution License (CC BY). The use, distribution or reproduction in other forums is permitted, provided the original author(s) and the copyright owner(s) are credited and that the original publication in this journal is cited, in accordance with accepted academic practice. No use, distribution or reproduction is permitted which does not comply with these terms. 